\title{
The restoration of the endangered Sambucus palmensis after 30 years of conservation actions in the Garajonay National Park: genetic assessment and niche modeling
}

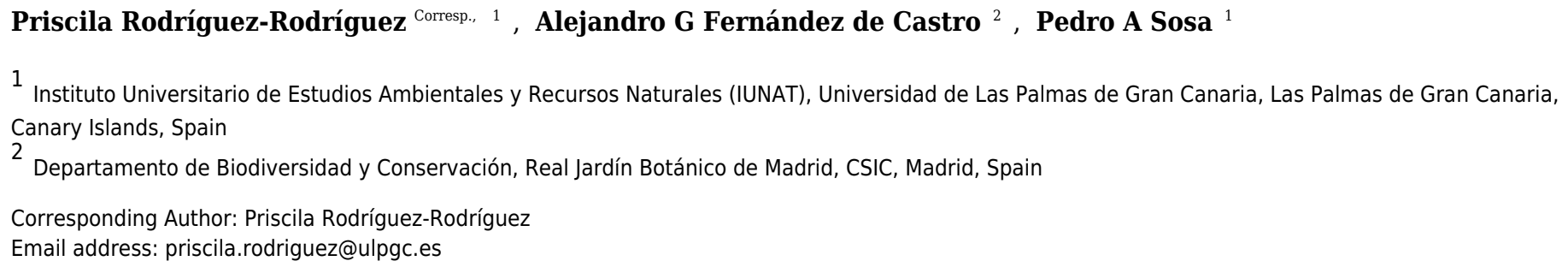

The translocation of individuals or the reinforcement of populations are measures in the genetic rescue of endangered species. Although it can be controversial to decide which and how many individuals must be reintroduced, populations can benefit from reinforcements. Sambucus palmensis is a critically endangered endemic to the Canary Islands. During the past 30 years, the Garajonay National Park (La Gomera) has carried out an intensive program of translocations using cuttings, due to the low germination rates of seeds. To assess the effect of the restorations on the population genetics of $S$. palmensis in La Gomera, we collected 402 samples from all the restored sites and all known natural individuals, which were genotyped with seven microsatellite markers. In addition, we conducted a species distribution modeling approach to assess how restorations fit the ecological niche of the species. Results show that there is a high proportion of clone specimens due to the propagation method, and the natural clonal reproduction of the species. Nonetheless, the observed heterozygosity has increased with the restorations and there still are private alleles and unique genotypes in the natural populations that have not been considered in the restorations. The population of Liria constitutes a very important genetic reservoir for the species. To optimize future reintroductions, we have proposed a list of specimens that are suitable for the extraction of seeds or cuttings in a greenhouse, as well as new suitable areas obtained by the species distribution models. 
1 The restoration of the endangered Sambucus palmensis after 30 years of conservation

2 actions in the Garajonay National Park: genetic assessment and niche modeling

3 Priscila Rodríguez-Rodríguez ${ }^{1}$, Alejandro G. Fernández de Castro ${ }^{2}$, Pedro A. Sosa ${ }^{1}$

4 1. Instituto Universitario de Estudios Ambientales y Recursos Naturales (IUNAT), Universidad de

5 Las Palmas de Gran Canaria, Campus Universitario de Tafira, 35017 Las Palmas de Gran Canaria, 6 España.

7 2. Departamento de Biodiversidad y Conservación, Real Jardín Botánico - CSIC, calle Claudio

8 Moyano 1, 28014 Madrid, España.

9 Corresponding author: priscila.rodriguez@ulpgc.es; +34928454543; ORCID: 0000-0002-7457-

$10 \quad 7596$ 


\section{ABSTRACT}

The translocation of individuals or the reinforcement of populations are measures in the genetic rescue of endangered species. Although it can be controversial to decide which and how many individuals must be reintroduced, populations can benefit from reinforcements. Sambucus palmensis is a critically endangered endemic to the Canary Islands. During the past 30 years, the Garajonay National Park (La Gomera) has carried out an intensive program of translocations

17 using cuttings, due to the low germination rates of seeds.

To assess the effect of the restorations on the population genetics of S. palmensis in La

19 Gomera, we collected 402 samples from all the restored sites and all known natural individuals, which were genotyped with seven microsatellite markers. In addition, we conducted a species distribution modeling approach to assess how restorations fit the ecological niche of the species. Results show that there is a high proportion of clone specimens due to the propagation method, and the natural clonal reproduction of the species. Nonetheless, the observed

24 heterozygosity has increased with the restorations and there still are private alleles and unique genotypes in the natural populations that have not been considered in the restorations. The population of Liria constitutes a very important genetic reservoir for the species. To optimize

27 future reintroductions, we have proposed a list of specimens that are suitable for the extraction of 28 seeds or cuttings in a greenhouse, as well as new suitable areas obtained by the species distribution models. 


\section{INTRODUCTION}

The preservation of endangered plant species usually involves population restorations,

33 either by reinforcement of the extant populations or the reintroduction of new populations.

34 Before starting restoration programs, biological information on the species must be first gathered

35 in order to determine the most important factors limiting the growth of the founding population

36 (Heywood and Iriondo 2003). The biological purpose of the restorations is to increase the

37 species' survival prospects by recovering its evolutionary potential and autonomous ecological

38 behavior (Godefroid et al. 2011). These measures often involve translocating genotypes across

39 geographic ranges. This is a very controversial practice in which the need to maximize genetic

40 diversity and avoid inbreeding depression is balanced against the maintenance of coadapted gene

41 complexes (outbreeding depression; Storfer 1999; Hufford and Mazer 2003; González-Pérez et

42 al. 2009). In this respect, it has been extensively argued that increasing gene flow largely

43 improves fitness and evolutionary potential of inbred populations, without high risks of

44 outbreeding depression (Frankham 2015). Nevertheless, many restoration programs have taken

45 place without prior knowledge of the genetic background of the populations. The genetic

46 variability within and between natural populations should be considered before starting

47 reintroductions and translocations of genotypes. Also, many reintroductions are performed

48 without analytical knowledge of the habitat and the autoecology of the species. Therefore, the

49 selection of areas for reintroduction is often decided on the basis of intuitive or informal

50 expertise, as the choice of unsuitable habitats is considered a frequent reason for failure

51 (Godefroid et al. 2011).

52 Oceanic islands ecosystems are generally threatened either by biological (inherent to

53 islands) or socio-economic factors. The biological causes are mainly habitat loss or degradation, 
54 small populations sizes and fragmentation, and the introduction of alien species or direct

55 predation. The socioeconomic factors are mainly due to demographic and economic growth

56 accompanied by a lack of natural resources management capacity, and with special relevance in

57 The Canary Islands, the high touristic pressure (Whittaker and Fernández-Palacios 2007;

58 Caujapé et al. 2010). Climate change is also considered a major threat to the island flora, which

59 could disrupt inter-specific mutualisms, or shift the elevation of cloud layers (Harter et al. 2015),

60 very important for humid ecosystems, such as the laurel forest.

61 In Macaronesia, the laurel forest is one of the best representations of this insular

62 vulnerability as it has experienced a major reduction since human colonization. In the Canaries,

63 most of the laurel forest disappeared after the arrival of Castilians ( $15^{\text {th }}$ century), affecting the

64 distribution and abundance of many species (de Nascimento et al. 2009; Fernández-Palacios et

65 al. 2011). Despite its slow recovery due to the abandonment of agricultural land, the extant laurel

66 forest represents $18 \%$ of its original area (Fernández-Palacios et al. 2011). However, the forests

67 in the Garajonay National Park in La Gomera, which have suffered less due to human

68 colonization than in the other islands (Nogué et al. 2013), are considered to be the best relicts of

69 laurel forest. Indeed, the island holds all the laurel forest types present in the Canary Islands,

70 with a high representation of endemic species (Fernández-Palacios et al. 2017). Therefore, La

71 Gomera constitutes an optimal scenario to test habitat management initiatives.

72 The present study used Sambucus palmensis as a model species to evaluate the

73 effectiveness of long-term conservation programs in clonal perennial species. Saúco or Canary

74 elderberry is a rare endemic of the Canarian Archipelago and is present in four of the seven main

75 islands (Arechavaleta et al. 2010): Tenerife, La Gomera, La Palma and Gran Canaria. It falls

76 within the category of "In danger of Extinction" in the Spanish Catalogue of Threatened Species 
77 and as "Endangered C2a" in the IUCN Red List (Marrero et al. 2011). In fact, it is one the tree

78 species at highest risk of extinction in the Canary Islands. These considerations are due to the

79 small number of naturally occurring individuals $(<100)$ in the four islands. Other factors that

80 could affect this threatened species are herbivory by goats and rats, habitat loss as well as forest

81 fires and change in land use (Fernández-López and Velázquez-Barrera 2011; Marrero et al.

82 2011). And in fact, signs of a recent genetic bottleneck were estimated in two populations in La

83 Palma and Tenerife (Sosa et al. 2010).

84 The latest census for $S$. palmensis in the Canary Islands confirmed that there exist 1387

85 specimens, with a low percentage of natural origin. The origin of the individuals is confusing due

86 to their connection to agricultural lands and cultivation, especially in Tenerife and La Gomera

87 (Marrero et al.- 2015) The highest number of individuals are currently found in La Gomera,

88 (1090), distributed in more than 12 sites in the surroundings of the Garajonay National Park.

89 Despite the high number of specimens, only 25 have been considered to be of natural origin,

90 while the rest are the result of restoration programs developed over more than 30 years (Marrero

91 et al. 2015). By the 1980s, the populations of La Gomera were reduced to a few individuals,

92 which led to the urgent need of restoration activities (Marrero et al. 1998; Marrero et al. 2015).

93 Later on, due to a fire that occurred in 2008 in La Gomera which cleared the laurel forest canopy,

94 the locality of Liria went through a population expansion, from four known individuals to the 40

95 individuals that we analyzed in this article (Fernández-López et al. 2014). In the early stages of

96 the conservation program, since germination rates were very low, the reintroduced specimens

97 were obtained through vegetative propagation by cuttings (Marrero et al. 1998). Surprisingly,

98 after these restorations, sexual propagation has been detected in climatically optimal years,

99 increasing the size of the restored sites (Marrero et al. 2015). Consequently, individuals obtained 
100 by cuttings or descendants of old reintroductions have been translocated to other sites, possibly

101 leading to a homogenization of the genetic structure. Although there has been a significant

102 increase in the number of individuals, the genetic background has not been considered in any of

103 the restorations. In the previous study of S. palmensis covering its entire distribution (Sosa et al.

104 2010), low genetic diversity, a high number of identical genotypes and overall exclusive alleles

105 were found in La Gomera. A strong connection with Tenerife was also detected, possibly due to

106 the anthropogenic transfer of individuals between islands. However, in the study by Sosa et al.

107 (2010), only three markers were polymorphic for La Gomera, which could have led to

108 misinterpretation of the number of genotypes.

109 The aims of this study were (1) to estimate changes in genetic diversity after the

110 restoration programs in La Gomera, (2) to identify the current genetic structure and the number

111 of identical genotypes in the populations, (3) estimate the topoclimatic suitability of S. palmensis

112 in La Gomera with natural and reintroduced occurrences and (4) to provide a background for

113 future conservation programs in the Garajonay National Park.

115 MATERIAL AND METHODS

116 Study species

117 Sambucus palmensis Link, (Sambucus nigra subsp. palmensis (Link) R. Bolli)

118 (Sambucaceae), It grows in the laurel forest vegetation zone between 600-1000 $\mathrm{m}$ a.s.1., with a

119 preference for shady and humid places. It can also be found on the margins of agricultural fields

120 being grown by locals due to its historical use for medicinal purposes (Beltrán et al. 1999;

121 Abdala et al. 2014). This tree can reach up to 4-6 $\mathrm{m}$, is a hermaphroditic taxon and the fruits can

122 be dispersed by birds (Marrero et al. 2011). Also, the species extensively propagates by 
123 vegetative reproduction, which has facilitated its reintroduction by cuttings. However, the low

124 regeneration capacity of the species and the high mortality rates of new individuals leads one to

125 think that Sambucus palmensis presents reproductive self-incompatibility and inbreeding

126 (Marrero et al. 1998).

127 Sample collection

128 The fieldwork was performed under the project 255/2011 funded by "Organismo

129 Autónomo de Parques Nacionales" and the sample collection was assisted by the Garajonay

130 National Park staff. Leaf samples from all the naturally occurring individuals (47), present in the

131 sites of Acebiños, Ancón de Candelaria, Liria, Meriga and Presa de Las Rosas, and a significant

132 representation of the reintroduced individuals from the whole distribution in La Gomera (355)

133 were collected during 2012 and 2013. The categories of natural or reintroduced were considered

134 according to the Garajonay National Park records and annotations. The individuals from Liria

135 and Presa de Las Rosas are all natural, with no reintroduced individuals. In total, 402 samples

136 were collected and genotyped for the study. They are distributed in 15 sites according to their

137 geographical distribution or management area for the National Park. The distribution of the

138 analyzed individuals and the sampling sites are represented in Fig.1. Young leaves for all

139 specimens were collected and stored in plastic bags with silica gel for their conservation.

\section{Microsatellite development and genotyping}

141 In this study, seven SSR markers were used for the genotyping of Sambucus palmensis

142 individuals in La Gomera. Five markers that were developed for Sambucus nigra (Clarke and

143 Tobutt 2006) and characterized for S. palmensis (Sosa et al. 2010) were tried for our set of

144 samples. However, only three of these markers (EMSn017, EMSn025, EMSn003) yielded

145 enough polymorphism in the La Gomera populations to be considered. Therefore, we developed 
146 four new microsatellite markers for S. palmensis to improve the accuracy of the genotypes,

147 coded as Sam_Tet2, Sam_Hex2, Sam_Hex1 and Sam_Tri8 (Supplemental S1).

148 DNA was extracted from silica-gel-dried young leaves using a modified 2 x CTAB protocol

149 (Doyle and Doyle 1987). DNA was subsequently purified with the commercial kit Gene Elute

150 PCR Clean-up (Sigma). After the characterization of the microsatellites, the whole set of samples

151 was extracted with Invisorb DNA Plant HTS 96 KIT INVISORB.

152 Microsatellite loci were selected from an Illumina paired-end shotgun library developed

153 by the company AllGenetics (University of A Coruña) using three probe mixes of S. palmensis.

154 We initially chose 20 primer pairs from this library of which 16 yielded some product and were

155 labelled. Finally, four primer pairs amplified consistently with more than two alleles and were

156 selected to complete the genotyping for all samples. For the initial testing, PCR was conducted

157 individually with each primer pair in a $25 \mathrm{uL}$ total reaction volume, which contained

158 approximately: $20 \mathrm{ng}$ of DNA 10 pmol of each primer, as well as PCR Master Mix until $25 \mathrm{uL}$

159 were completed (Reddy-Mix, ABgene, Surrey, UK). Amplifications were performed using the

160 following conditions: 3 min denaturation at $95^{\circ} \mathrm{C}, 35$ cycles of $30 \mathrm{~s}$ denaturation at $95^{\circ} \mathrm{C}, 30 \mathrm{~s}$

161 annealing at $50-62^{\circ} \mathrm{C}$, and $72^{\circ} \mathrm{C}$ for $1.5 \mathrm{~min}$; followed by $5 \mathrm{~min}$ elongation at $72^{\circ} \mathrm{C}$. Reverse

162 primers were color-labelled at the 5'-end with 6-FAM, PET, NED or VIC.

163 Once the new markers where characterized, we conducted the subsequent multiplex

164 amplifications for the seven primer pairs using the QIAGEN Multiplex Kit (QIAGEN). PCR

165 were performed in $15 \mu \mathrm{L}$ reaction volumes: $7.5 \mu \mathrm{L}$ of Multiplex PCR Master Mix, $1.5 \mu \mathrm{L}$ primer

166 mix (containing $0.2 \mu \mathrm{M}$ of each primer in TE), $1.5 \mu$ of Q-solution, 20-40 ng of DNA and $\mathrm{dH}_{2} 0$.

167 Multiplexing was carried out in two primer groups as indicated in Supplemental S1. Following

168 the manufacturer's instructions, PCRs consisted of a Touchdown protocol with the thermal 
169 conditions: $15 \mathrm{~min}$ at $95^{\circ} \mathrm{C}, 10$ cycles of $30 \mathrm{~s}$ at $94^{\circ} \mathrm{C}$, annealing for $90 \mathrm{~s}$ at $65^{\circ} \mathrm{C}$ with a decrease

170 of $0.5^{\circ} \mathrm{C}$ per cycle and $60 \mathrm{~s}$ at $72^{\circ} \mathrm{C}$, followed by 20 cycles of $30 \mathrm{~s}$ at $94^{\circ} \mathrm{C}$, annealing for $90 \mathrm{~s}$ at

$17155^{\circ} \mathrm{C}$ and $60 \mathrm{~s}$ at $72^{\circ} \mathrm{C}$, with a final extension of $30 \mathrm{~min}$ at $60^{\circ} \mathrm{C}$. All the products from both

172 simple and multiplex PCR were detected on an ABI 3730 Genetic Analyzer and fragments were

173 sized against the LIZ (500-250) size standard (Applied Biosystems, Inc.) and visualized using

174 Genemapper 4.0 (Applied Biosystems, Inc.). We identified allele peak profiles at each locus and 175 assigned a genotype to each individual.

176 Statistical analysis

177 To estimate the incidence of clonality and identify the different genotypes for $S$.

178 palmensis in La Gomera, multilocus matches were identified with GenAlex version 6.5 (Peakall

179 and Smouse 2012). Unique genotypes (only in one individual) were coded with consecutive

180 numbers, and shared genotypes (in more than one individual) were coded with letters, from A to

181 ZZ. With the same software, basic genetic diversity indices: average of alleles per locus $(\mathrm{Na})$;

182 number of private alleles $(P a)$, rare alleles (present in four sites or less; $R a$ ), observed $\left(H_{\mathrm{o}}\right)$, and

183 unbiased expected $\left(H_{\mathrm{e}}\right)$ heterozygosities for each locus and locality were estimated. Measures of

184 allelic $(A r)$ and private allelic richness (Par) were calculated using HP-RARE 1.0 (Kalinowski

185 2005), which uses rarefaction to correct for sampling error. To detect differences in genetic

186 diversity before and after the restoration programs, the indices calculated for each locality were

187 also estimated for the restored and natural individuals separately. Individual heterozygosity was

188 also calculated to provide a list of the most suitable individuals for restoration programs, in order

189 to increase the fitness of the founder individuals and their offspring (Engelhardt et al. 2014). On

190 this list, individuals with unique genotypes, a high individual heterozygosity and presence of rare

191 alleles were identified. 
193 (Van Oosterhout et al. 2006). BOTTLENECK 1.2.02 software was used to identify any recent

194 genetic drift events in the original set of individuals (Cornuet and Luikart 1996). The two-phase

195 mutation model (TPM), which is a modification of the stepwise mutation model (SMM), was

196 implemented and shows to be a better fit for most microsatellite data sets (Piry et al. 1999). In

197 the TPM model, to optimize the most sensitive values for microsatellites, a proportion of SMM

198 in the TPM $=0.000$ and a variance of the geometric distribution for TPM $=0.36$ were chosen.

199 Allele frequency information was analyzed using a nested analysis of molecular variance

200 (AMOVA) (Excoffier et al. 1992) with ARLEQUIN software. The analyses were conducted with

201 two different approaches, with the individuals being grouped either by locality or their origin

202 (natural versus restored). In addition, a principal coordinate analysis (PCoA), using the

203 covariance standardized method of pairwise codominant genotypic distances among individuals,

204 was implemented with GENALEX version 6.5 (Peakall and Smouse 2012).

205 To estimate the current genetic structure of the populations, all the genotypes were

206 screened using a Bayesian admixture procedure with the software STRUCTURE (Pritchard et al.

207 2000). The model was assumed to be of population admixture and correlated allele frequencies.

20810 independent runs were conducted for each value of $K$ (from 1 to 15 ) and analysis consisted of

209 a $10^{5}$ burn-in period replicated and a run length of $10^{6}$ replicates. The optimal number of clusters

210 was found by the $\Delta \mathrm{K}$ method (Evanno et al. 2005) visualized with STRUCTURE HARVESTER

211 (Earl and vonHoldt 2012). Results of 10 replicates of the best fit $K$ were processed using

212 CLUMPP 1.1.2 (Jakobsson and Rosenberg 2007) to determine the optimal clustering. The

213 STRUCTURE HARVESTER results for the election of the optimal $K$ are presented in

214 Supplemental S2. 


\section{Species Distribution Modeling}

216 The explanatory power of SDMs (Species Distribution Models) is often improved when

217 accurate resolutions of spatial predictors are used (Lassueur et al. 2006; Austin and Van Niel

218 2011). We therefore developed a set of accurate spatial climate layers at a 50-meter resolution,

219 based on the network of meteorological stations of the whole archipelago (data provided by

220 AEMET, www.aemet.es). Stations with 10 or more years of climate records were filtered for the

221 models. For the monthly variables of minimum and maximum temperature and precipitation, a

222 generalized additive model (GAM) with altitude, northness, latitude and longitude as predictor

223 variables was developed. The best model was selected based on the AIC scores and then

224 projected to La Gomera island. To account for spatial biases of the models, residuals of each

225 model in each meteorological station were used to develop an interpolated map of residuals for

226 each variable by ordinary kriging. This interpolated layer was added to the predicted value of the

227 GAM model to obtain the final layers of each monthly variable. The final dataset of monthly

228 variables was used to develop the bioclimatic variables described by Hijmans et al. (2005), using

229 the 'dismo' package in R (Hijmans et al. 2015). Two topographic predictors: slope and

230 topographic index (TPI), derived from the digital elevation model (DEM) of the archipelago

231 were also incorporated.

232

441 reintroduced presence cells were recorded in total at 50 meter working resolution, 47

233

were natural presences in La Gomera and 9 recorded in Tenerife and La Palma. 51 presences

234 were discarded as they could not be unambiguously assigned to natural or reintroduced

235 populations in Tenerife and La Palma. To select climatic predictor variables for the modeling

236 procedure first a correlation analysis was conducted for the values of the variables in the cells

237 where the species was present with the R package 'ecospat' (Broennimann et al. 2014), which 
238 returned a value of 4 predictor variables. Then a PCA was conducted, and the 11 predictors

239 which obtained the highest scores along the first three axes were retained. Finally, a hierarchical

240 partitioning analysis was conducted (Chevan and Sutherland 1991), with 'hier.part' R package

241 (Walsh \& Mac Nally 2013), to select among those 11 variables, the 5 showing the highest

242 independent contributions according to ecospat. These were bioclimatic variables 2, 10, 12 and

24315 (temperature range, mean temperature of warmest quarter, annual precipitation, precipitation

244 seasonality, respectively) and slope.

245 Three different niche modeling procedures were conducted with biomod2 package (Thuiller et

246 al. 2009). The first one was calibrated with natural occurrences only, and the second one with

247 both natural and introduced presences. Finally, the third one was calibrated with introduced

248 occurrences only, to evaluate the model with the natural occurrences and obtaining therefore an

249 evaluation of the introduction with independent data. In each of the three modeling procedures, 5

250 datasets were developed containing presence points and pseudoabsences were generated

251 randomly only in unaltered habitats of the island. This was done to avoid generating

252 pseudoabsences in potentially suitable areas were the species was not appearing due to habitat

253 destruction instead of ecological constraints. In the third modeling procedure, pseudoabsences

254 were also generated randomly but avoiding the areas where natural populations existed. In each

255 of the three procedures the number of pseudoabsences differed: with natural occurrences, a total

256 of 200 pseudoabsence points was generated, which were weighted in the models to account for

257 the same importance as presences. With both natural and reintroduced presences, and with only

258 introduced presences, the number of pseudoabsences matched the number of presences.

259 Six algorithms available in biomod2 were used: generalised linear models (GLM),

260 generalised additive models (GAM), both with stepwise selection, boosting regression (GBM), 
261 multiadaptive regression splines (MARS), annual neural networks (ANN), and random forest

262 (RF). 10 runs of each presence-pseudoabsence dataset were run for the first two modeling

263 approaches. In each run, 85\% of data was randomly selected for calibration and the rest for

264 model evaluation. The third procedure was evaluated using the natural occurrences of the

265 species. Models were evaluated by means of TSS and ROC scores. Any model with a score

266 below 0.8 for any of the two metrics was excluded for the ensemble model. The remaining

267 models were retained to build an ensemble model based on the contribution of each individual

268 model weighted according to the TSS score.

269

270

\section{RESULTS}

271

All microsatellite markers used for this study yielded enough polymorphism to identify

272 the possible number of genotypes in the sampling sites analyzed and to detect possible identical

273 genotypes. Out of the 402 individuals sampled, 147 different genotypes were found. 84 of these

274 were unique genotypes (genotypes detected in only one individual), and 63 were shared

275 genotypes (from more than one individual) (Table 1). We found some genotypes corresponding

276 to a high number of individuals, for example the genotype JJ that matched 81 samples, the

277 genotype $\mathrm{V}$ that matched 30 genotypes and the genotype UU matched with 15 individuals. The

278 remaining genotypes matched between 2 and 10 individuals each. A detailed list of genotypes

279 per locality is shown in Supplemental S3. The sampling site with the highest number of unique

280 genotypes was the locality of Liria (29), where all individuals are natural, followed by the

281 restored sites of El Rejo (18) and Meriga (11). The percentages of unique genotypes per locality

282 were also higher in Presa de las Rosas (100\%) and Liria (82.86 \%) than in the restored sites,

283 which ranged from $0.00 \%$ to $66.67 \%$. 

values were similar across sites. The expected heterozygosity ranged from 0.357 (Presa de las Rosas) to 0.495 (Raso de la Bruma). The observed heterozygosity values did show higher 287 differences across sites, ranging from 0.366 (El Cedro) to 0.714 (Cañada Jorge). Liria and Meriga were the only sites with private alleles, and Liria presented the highest rarefied private allelic richness at 0.26 (Table 2). Moreover, eight sites presented rare alleles, which were present in four sites or less (Supplemental S4). Between restored and natural groups, the natural group displayed higher allelic richness and a greater presence of private alleles, but a lower observed heterozygosity than in the restored groups. The results of tests to detect recent bottleneck events in the natural individuals, considering them as a single population, were not significant for any of the tests implemented. Only the locus Sam_Hex2 presented evidence of null alleles in El Cedro, El Rejo and Meseta Vallehermoso.

AMOVA results were similar in the two approaches tested (Table 3). In both cases, the variance between individuals within groups was higher than that between groups. The variance between was $2.5 \%$ and $2.9 \%$, between sites and between the natural and restored groups respectively. This low variance shows the lack of differentiation between the sitesstudied and between the natural and restored groups. As with the AMOVA results, the PCoA, with a total explanation of $62.06 \%$ did not reveal a clear aggrupation between natural and restored individuals (Fig. 2). and the mean of log-likelihood values $(K=2$ and $K=5)$ (Supplemental S2). Therefore, both

305 possibilities are shown in Fig. 2. In $\mathrm{K}=2$, all individuals were admixed in the two clusters 306 described with evident lack of genetic structure. In the representation of K=5, "Liria" was the 
307 only sampling site with a high assignation to a single cluster. The other sites presented admixture

308 of the five clusters, except for "Cañada Jorge", but in that locality, all individuals shared the

309 same genotype (Table 1).

310 Finally, we proposed a list with the 25 most suitable individuals with which to build a

311 conservation genetic program to enhance the genetic variability of the populations. Individuals

312 with unique or rare genotypes, which also presented a high individual heterozygosity and private

313 or rare alleles were considered (Supplemental S5).

\section{Species distribution modeling}

315 The PCA analysis conducted with all spatial predictors considered accounted for a 96.35

$316 \%$ of the variance and showed patent differences between the niche of introduced and natural

317 populations (Supplemental S6), corresponding to differences in the precipitation seasonality

318 (bio04) and annual precipitation (Supplemental S7). Also, there were visible contributions of

319 three intertwined variables: precipitation of the wettest month, precipitation of the wettest quarter

320 and precipitation of the coldest month (variables 13,16,19); natural populations showed less

321 temperature seasonality whereas they occurred in areas with lower precipitation (Supplemental

322 S7).

323 The evaluations of the two modeling procedures differed significantly between

324 occurrence datasets (GLMM, $\mathrm{F}_{2,317}=20.73, \mathrm{P}<=3.575 \times 10^{-9}$, pseudoabsence dataset and model

325 run as random effects) and models (GLMM, $\left.\mathrm{F}_{5,317}=8.5499, \mathrm{P}<=3.575 \times 10^{-9}\right)$, with the

326 introduced model showing better performance (Supplemental S8). In total, 66 models were not

327 included with the natural dataset, 64 with the introduced one (evaluated against the natural

328 occurrences) and 104 when considering all occurrences. Hence, the ensemble modeling was built

329 with 85,88 , and only 51 respectively under the demanding quality threshold set for filtering 
330 models. However, the average TSS score for each modeling dataset was above 0.7 , which is

331 considered as fair (natural dataset, TSS=0.79, introduced 0.78, all=0.79) (Guisan et al. 2017).

332 Models in general showed therefore good performance, yet many of them were not included as

333 they showed values around $0.7-0.8$ score.

334 The suitable areas declared by the three modeling procedures projected suitable areas in

335 the northern parts of the island in areas exposed to humid trade winds, but were conspicuously

336 different (Fig. 3): the suitable areas for S. palmensis appeared in the northern-northeastern

337 section of La Gomera when the model was calibrated with natural presences only. Models

338 calibrated with introduced occurrences only showed on the contrary slightly more extended

339 potential distribution for the species encompassing eastern regions. Regarding the comparison

340 between natural calibration and the model calibrated with all ocurrences, the second showed

341 lower suitability but also a lower threshold. Therefore, the whole model showed a higher

342 extension. The potential distribution fell within protected areas only partially, with 1345 cells

343 inside protected areas out of $5045(26.83 \%)$. Only 17 cells did fall within the limits of

344 Garajonay National Park.

\section{DISCUSSION}

An integrative approach towards the conservation of endangered species, with the combination of molecular and modeling tools, is starting to be more considered, although few examples can still be found on islands (Noël et al. 2010, Fernández-Mazuecos et al. 2014, Silva et al. 2015). Our results suggest that the restoration programs of Sambucus palmensis in La

351 Gomera have greatly improved the genetic status and distribution range of this species in the

352 island. Although there is a high proportion of clonal specimens, natural regeneration has 
353 occurred in the restored sites, generating new genotypes and alleles that were not present in the

354 original populations. Moreover, the restored sites are occupying new climatic suitable areas,

355 which has led to an expansion of the distribution, compared to the natural populations.

356 Nonetheless, there are still some major concerns in the conservation of $S$. palmensis, such as the

357 difficulties in sexual reproduction, or the high mortality rates of young plants.

358 The genetic diversity estimates for La Gomera are higher than those reported by Sosa et

359 al. (2010). This is an expected result due to the increase in the number of polymorphic

360 microsatellite markers. In the aforementioned study, only five markers were included, with $80 \%$

361 of polymorphism in La Gomera. Moreover, the high number of samples taken for this more

362 detailed survey are a better representation of the real populations. Despite the new findings, the

363 genetic diversity in La Gomera might possibly still be lower than in Tenerife and La Palma,

364 whose populations have not yet been analyzed with the new set of markers.

365 Since the article by Sosa et al. (2010) was published, the knowledge of genetic diversity

366 measured with microsatellite markers in oceanic endemics has significantly increased (Takayama

367 et al. 2015, White et al. 2016, Yang et al. 2017). Therefore, we are now able to confirm that $S$.

368 palmensis presents moderate levels of genetic diversity for a rare endemic (Sosa et al. 2011).

369 Overall, outcrossing species present higher diversity than selfing species (Hamrick and Godt

370 1996; Pérez de Paz and Caujapé-Castells 2013). In comparison with other self-incompatible

371 species, the rare endemics Bethencourtia hermosae (Rodríguez-Rodríguez et al. 2018) or the

372 highly threatened species of the genus Commidendrum from St Helena island (Gray et al. 2017)

373 presented very low expected heterozygosity levels. But those species are single-island endemics

374 and habitat-restricted. S. palmensis is present in four islands and was probably even more

375 widespread in the past (Beltrán et al. 1999; Sosa et al. 2010). In this respect, S. palmensis 
376 revealed similar heterozygosity values to other endemics such as the widespread dioecious palm

377 Phoenix canariensis (Saro et al. 2015) or the laurel forest tree Ilex canariensis (Sosa et al. 2013).

378 Effects of restoration activities on genetic diversity and structure

379 Because of the main propagation method, by the reintroduction of cuttings, we have

380 detected a high presence of clonal specimens. Just like its relative Sambucus nigra, S. palmensis

381 also presents natural vegetative reproduction (Marrero et al. 1998; Bañares et al. 2004).

382 Therefore, natural clones can be found in Liria, which presented $17.14 \%$ of shared genotypes.

383 But the percentage of shared genotypes in the other populations that have been restored is much

384 higher, due to the extensive reintroduction of clone specimens. On the other hand, natural

385 regeneration has been detected in some of the sites, with the appearance of new unique

386 genotypes and private alleles in the restored sites. Nonetheless, the private alleles that are present

387 in the restored sites could have come from natural individuals which are now dead and not

388 included in this study. Therefore, the translocation of genotypes may be increasing the chances

389 of sexual reproduction, as has already been detected in some of the restored sites (Marrero et al.

390 2015).

391 The percentages of variation found between populations are low for an outcrossing

392 species (Hamrick and Godt 1996), and they are also lower than that found by Sosa et al. (2010)

393 among populations within islands (15\%). The variation values detected are also lower than those

394 found for the relative Viburnum treleasi, which has low variation among populations and also

395 presents both sexual and clonal reproduction (Moura et al. 2013). Therefore, there is evidence

396 that the admixture of genotypes across populations have favored the gene flow across the habitat

397 range of S. palmensis in La Gomera. In the STRUCTURE results, Liria, which represents the

398 best-conserved natural population in La Gomera, was the only locality that presented less 
399 admixture of individuals. The high number of unique genotypes and the presence of private

400 alleles in Liria suggest that these individuals have been rarely used as a genetic source in the

401 restoration programs, although some individuals were used for propagation before the expansion

402 in 2008 (Ángel Fernández-López, personal comment). Although we did not find a sign of recent

403 bottleneck events in the natural source, most of the individuals came from Liria, which has

404 naturally increased its population size since the monitoring programs started. Thus, bottleneck

405 events in the other natural sites are difficult to infer, as only a few individuals have remained.

406 Overall, there was a light increase in the observed heterozygosity in the restored sites.

407 These results, together with the high admixture found in the genetic structure, also explain the

408 artificial gene flow implemented with the restorations. Outcrossing of inbred isolated populations

409 is playing a major role in the genetic rescue of endangered species (Love Stowell et al. 2017),

410 but a balance between genetic rescue and "outbreeding depression" must be found in the

411 management of populations, paying attention to the particular needs in each case (Hufford and

412 Mazer 2003). In addition, the habitat and climatic continuity of the laurel forest in La Gomera,

413 together with the outcrossing system of the species could have favored the gene flow between

414 the past populations of S. palmensis, hindering high population differentiation or local

415 adaptation. Even if the translocations of genotypes have led to outbreeding depression, the

416 advantages of outcrossing can be greater, especially for self-incompatible species, as it increases

417 the chances of finding available mates (Willi et al. 2007; Pickup and Young 2008). Despite the

418 increased observed heterozygosity, the number of alleles (the average of alleles per locus and

419 allelic richness) are still lower in the restored individuals compared to the natural ones. These

420 results can be taken as positive, because they indicate that the restored sites can still benefit from

421 a greater outcrossing and admixture with the natural individuals within La Gomera. 


\section{Insights from SDMs}

423 This is the first modeling approach at such accurate scale developed for La Gomera. The

424 development of three models based on different datasets for calibration allowed to draw two

425 conclusions about the accuracy of the decision on the placement of the reintroductions. The PCA

426 and the projections of the models clearly show differences in the ecological niche of the natural

427 populations and the introduced ones, which survived successfully under other conditions. Natural

428 populations were localized in areas with lower precipitation and allowed to predict only a part of

429 the total potential area. From the discrepancy between the two niches, three main conclusions

430 can then be drawn.

431 The first one is that the natural populations, which are very restricted, show a truncated

432 niche, as they only reflected part of the ecological conditions of the species and many individual

433 models did not reach the quality threshold to be included. From the conservation perspective, this

434 is a frequent episode for threatened species witnessing the reduction of the realized niche, and a

435 challenge for modeling procedures which normally should assume niche equilibrium This is the

436 first case in the Canaries of assessment of niche filling of a species through practical

437 reintroduction. Indeed, this kind of assessments supported by independent presence records are

438 rather infrequent (Guisan et al. 2017). Therefore, the second conclusion is that the selection

439 criteria of enclaves for reintroduction was appropriate, given the physiological performance of

440 individuals, and despite the climatic conditions did not match those of the scarce natural

441 remaining populations. The quality of the models that considered introduced occurrences,

442 assessed either with independent data or not, was significantly higher than considering natural

443 occurrences only, with few models failing. The fairly higher number of introduced occurrences

444 on the other hand can explain why the potential distribution predicted by the model calibrated 
445 with introduced occurrences and absences within La Gomera is higher than any other model.

446 Finally, models served as a tool to identify further areas for protection. At present, protected

447 areas other than Garajonay National only cover a quarter of the potential distribution.

\section{Recommendations for conservation actions}

449 One of the main purposes of restoration ecology is to simulate the characteristics of the

450 natural populations (Pavlik 1996) and the restored sites do not show diminished levels of genetic

451 diversity compared to the original populations, despite the high number of clonal specimens.

452 Also, SDMs support that reintroduced specimens match properly missing ecological conditions

453 in the remaining populations. However, to improve the sexual regeneration in future

454 reintroductions, further studies of the reproductive biology of $S$. palmensis are encouraged. The

455 detection of the possible causes of self-incompatibility would help to increase the level of

456 available mates and therefore gene flow and offspring. Also, more demographic studies such as

457 that carried out in Meseta Vallehermoso (Marrero et al. 2015), will help to monitor the fitness

458 and survival of restored sites over time. The combination of demographic and genetic studies is

459 vital to ensure the recovery of endangered species (Oostermeijer et al. 2003).

460 As an urgent measure to maintain the genetic diversity of S. palmensis in La Gomera, we

461 have already provided a list to the Garajonay National Park managers with the best candidates

462 for a conservation genetic program (Supplemental S5). We also believe that it is important to

463 avoid the genotypes detected in this study that have been extensively used in some sites. As

464 indicated in Vergeer et al. (2004), we would also suggest increasing the number of unrelated

465 seed producer individuals to create sustainable and viable populations, which would also avoid

466 inbreeding processes. Since propagation by cuttings is the most viable way of reintroducing new

467 individuals, the consideration of all individuals with unique genotypes for future reintroductions 
468 is also a conservation measure to be taken into account. Although it is possible that individuals

469 from Tenerife were introduced in the past (Sosa et al. 2010), we consider that there is enough

470 genetic variability in La Gomera to continue the restoration programs using the genotypes that

471 are currently present on the island. Moreover, the suitability model based on the whole dataset of

472 occurrences is a valid tool to identify other suitable areas for further reintroductions or

473 translocations. The fact that the current S. palmensis' populations in La Gomera are within a

474 National Park figure, clearly has benefit the success of the restoration programs, in respect to the

475 populations in other islands. Although we have found suitable areas out of Garajonay that could

476 be useful in future reintroduction attempts. Therefore, it is important to take into consideration

477 endemic rarity in the design of protected areas (Irl et al. 2017).

478 It has been detected that good germination rates and seedling establishment highly

479 depends on years of good precipitation (Marrero et al. 2015). But the long survival of individuals

480 is determined by the clearance of the forest, reason why the Liria population expanded after the

481 fire in 2008. Although introduced herbivores are a major threat for the island endemic flora

482 (Reaser et al. 2007, Garzón-Machado et al. 2010, Irl et al. 2014), the laurel forest is not inhabited

483 by rabbits, and the Garajonay National Park tries to control the effects of feral goats and sheep.

484 However, predation of the fruits and leaves by rats has been observed (Ángel Fernández,

485 personal comment). In this sense, we consider of importance to favor the establishment of new

486 seedlings by manually clearing the canopy forest in the surroundings of $S$. palmensis individuals

487 and a thorough control of invasive herbivores.

488 On a long-term basis, this case study will provide a great deal of information regarding

489 the consequences of restoration actions in self-incompatible clonal species. Moreover, these

490 results can serve as a guideline for the restoration programs in Tenerife, La Palma and Gran 
491 Canaria, whose island governments are also restoring S. palmensis populations. For example, in

492 Gran Canaria, only two naturally occurring individuals and some cultivars were found prior to

493 the reintroductions. Therefore, a better knowledge of the genetic background of the restored

494 individuals and the climatic suitability of the species would increase the success and long

495 survival of the populations.

496

497 ACKNOWLEDGMENTS

498 We thank Ángel Fernández, Sito Chinea and Ángel García from Garajonay National Park and

499 the colleagues Agustín Naranjo Cigala, Claudio Moreno Medina, Juan José Robledo Arnuncio,

500 Miguel Ángel González, Pedro Luis Pérez de Paz and Leticia Curbelo for the help in the samples

501 collection and the laboratory work.

502

503 REFERENCES

504 Abdala S, Dévora S, Martín-Herrera D, Pérez-Paz P (2014) Antinociceptive and anti-

505 inflammatory activity of Sambucus palmensis Link, an endemic Canary Island species. J

506 Ethnopharmacol 155:626-632. doi: 10.1016/j.jep.2014.06.002

Arechavaleta M, Rodríguez S, Zurita N, García A (2010) Lista de especies silvestres de Canarias 508 (hongos, plantas y animales terrestres). Gobierno de Canarias

Austin MP, Van Niel KP (2011) Improving species distribution models for climate change

$510 \quad$ studies: variable selection and scale. J Biogeogr 38:1-8. doi: 10.1111/j.13652699.2010.02416.x

512 Bañares A, Blanca G, Gúemes J, Moreno JC, Ortiz S (2004) Atlas y Libro Rojo de la Flora 
513 Vascular Amenazada de España. Dirección General de Conservación de la Naturaleza,

$514 \quad$ Madrid

515 Beltrán E, Wildpret W, León M, García A, Reyes J (1999) Libro rojo de la flora Canaria

516 contenida en la Directiva-Hábitats Europea. Dirección de Conservación de la Naturaleza,

$517 \quad$ Ministerio de Medio Ambiente, La Laguna

518 Broenniman O, Petitpierre B, Randin CF, Engler R, Breiner F, D'Amen M, Pellissier L, Pottier J,

519 Pio D, Mateo RG, Di Cola V, Hordijk W, Dubuis A, Scherrer D, Salamin N, Guisan A et

520 al. (2014) ecospat: Spatial ecology miscellaneous methods. R package version

$521 \quad$ 1.0. http://CRAN.R-project.org/package=ecospat

522 Caujapé-Castells J, Tye A, Crawford DJ, Santos-Guerra A, Sakai A, Beaver K, Lobin W,

523 Vincent Florens FB, Moura M, Jardim R, Gómes I (2010) Conservation of oceanic island

524 floras: Present and future global challenges. Perspect Plant Ecol Evol Syst 12:107-129. doi:

$525 \quad 10.1016 / j$.ppees.2009.10.001

526 Chevan A, Sutherland M (1991) Hierarchical Partitioning. Am Stat 45:90-96. doi:

527 $10.1080 / 00031305.1991 .10475776$

528 Clarke JB, Tobutt KR (2006) Development of microsatellite primers and two multiplex

529 polymerase chain reactions for the common elder (Sambucus nigra). Mol Ecol Notes

$530 \quad 6: 453-455$. doi: $10.1111 / \mathrm{j} .1471-8286.2006 .01270 . \mathrm{x}$

531 Cornuet JM, Luikart G (1996) Power Analysis of Two Tests for Detecting Recent Population

532 Bottlenecks From Allele Frequency Data. Genetics 144:2001-2014

533 de Nascimento L, Willis KJ, Fernández-Palacios JM, Criado C, Whittaker RJ (2009) The long-

$534 \quad$ term ecology of the lost forests of la Laguna, Tenerife (Canary Islands). J Biogeogr 36:499-

535 514. doi: 10.1111/j.1365-2699.2008.02012.x 
536 Doyle JJ, Doyle JL (1987) A rapid DNA isolation procedure for small quantities of fresh leaf

537 tissue. Phytochem Bull. doi: 10.2307/4119796

538 Earl DA, vonHoldt BM (2012) STRUCTURE HARVESTER: A website and program for

539 visualizing STRUCTURE output and implementing the Evanno method. Conserv Genet

$540 \quad$ Resour 4:359-361. doi: 10.1007/s12686-011-9548-7

541 Engelhardt KAM, Lloyd MW, Neel MC (2014) Effects of genetic diversity on conservation and

542 restoration potential at individual, population, and regional scales. Biol Conserv 179:6-16.

543 doi: $10.1016 /$ j.biocon.2014.08.011

544 Evanno G, Regnaut S, Goudet J (2005) Detecting the number of clusters of individuals using the

545 Software STRUCTURE: A simulation study. Mol Ecol 14:2611-2620. doi: 10.1111/j.1365-

$546 \quad 294 X .2005 .02553 . x$

547 Excoffier L, Smouse PE, Quattro JM (1992) Analysis of molecular variance inferred from metric

548 distances among DNA haplotypes: Application to human mitochondrial DNA restriction

549 data. Genetics 131:479-491

550 Fernández-López ÁB, Gómez-González LAG, Gómez M (2014) Garajonay después del gran

551 incendio de 2012. In: Investigación, gestión y técnica forestal, en la región de la

552 Macaronesia. Colegio de Ingenieros de Montes, pp 201-226

553 Fernández-López Á, Velázquez-Barrera ME (2011) Programa de recuperación de especies

554 amenazadas del Parque Nacional de Garajonay. San Sebastián de La Gomera, Tragsatec.

555 Fernández-Mazuecos M, Jiménez-Mejías P, Rotllan-Puig X, Vargas P (2014) Narrow endemics

556 to Mediterranean islands: Moderate genetic diversity but narrow climatic niche of the

557 ancient, critically endangered Naufraga (Apiaceae). Perspect Plant Ecol Evol Syst 16:190- 
Fernández-Palacios JM, Arévalo JR, Balguerías E, Barone R, Delgado JD, de Nascimento L,

560 Elias RB, Fernández-Lugo S, Méndez J, Naranjo Cigala A, Menezes de Sequeira M, Otto R 561 (2017) La Laurisilva. Canarias, Madeira y Azores. Macaronesia Editorial, Santa Cruz de $562 \quad$ Tenerife

563 Fernández-Palacios JM, De Nascimento L, Otto R, Delgado JD, García-Del-Rey E, Arévalo JR, 564 Whittaker RJ. (2011) A reconstruction of Palaeo-Macaronesia, with particular reference to 565 the long-term biogeography of the Atlantic island laurel forests. J Biogeogr 38:226-246. 566 doi: $10.1111 / \mathrm{j} .1365-2699.2010 .02427 . \mathrm{x}$

567 Frankham R (2015) Genetic rescue of small inbred populations: meta- analysis reveals large and 568 consistent benefits of gene flow. Mol Ecol 24:2610-2618. doi: 10.1111/mec.13139

569 Garzón-Machado V, González-Mancebo JM, Palomares-Martínez A, Acevedo-Rodríguez A, 570 Fernández-Palacios JM, Del-Arco-Aguilar M, Pérez-de-Paz PL (2010) Strong negative 571 effect of alien herbivores on endemic legumes of the Canary pine forest. Biol Conserv 572 143:2685-2694. doi: 10.1016/J.BIOCON.2010.07.012

573 Godefroid S, Piazza C, Rossi G, Buord S, Stevens AD, Aguraiuja R, Cowell C, Weekley CW, 574 Vogg G, Iriondo JM, Johnson I, Dixon B, Gordon D, Valentin B, Bjureke K, Koopman R, 575 Vicens M, Virevaire M, Vanderborght T (2011) How successful are plant species 576 reintroductions? Biol Conserv 144:672-682. doi: 10.1016/j.biocon.2010.10.003

577 González-Pérez MÁ, Sosa PA, Batista FJ (2009) Genetic variation and conservation of the 578 endangered endemic Anagyris latifolia Brouss. ex Willd. (Leguminosae) from the Canary 579 Islands. Plant Syst Evol 279:59-68. doi: 10.1007/s00606-009-0146-z 
580 Gray A, Perry A, Cavers S, Eastwood A, Biermann M, Darlow A, Thomas V, Lambdon P (2017)

581 Hybrid plants preserve unique genetic variation in the St Helena endemic trees

582 Commidendrum rotundifolium. Conserv Genet 18:241-246.

583 Guisan A, Thuiller W, Zimmermann N (2017) Habitat Suitability and Distribution Models: with 584 Applications in R, 1st edn. Cambridge Universtiy Press, Cambridge

585 Hamrick J, Godt MJW (1996) Effects of life history traits on genetic diversity in plant species.

586 Philos Trans Biol Sci 351:1291-1298. doi: 10.1098/rstb.1996.0112

587 Harter DE V, Irl SDH, Seo B, Steinbauer MJ, Gillespie R, Triantis KA, Fernández-Palacios JM, 588 Beierkuhnlein C (2015) Impacts of global climate change on the floras of oceanic islands -

589 Projections, implications and current knowledge. Perspect Plant Ecol Evol Syst 17:160-183.

$590 \quad$ doi: $10.1016 /$ j.ppees.2015.01.003

591 Heywood VH, Iriondo JM (2003) Plant conservation: old problems, new perspectives. Biol

592 Conserv 113:321-335. doi: 10.1016/S0006-3207(03)00121-6

593 Hijmans RJ, Cameron SE, Parra JL, Jones PG, Jarvis A (2005) Very high resolution interpolated

594 climate surfaces for global land areas. Int J Climatol 25:1965-1978. doi: 10.1002/joc.1276

595 Hijmans RJ, Phillips S, Leathwick J, Elith J (2015) dismo: species distribution modeling. R

596 package version 1.0-12. http://CRAN.R-project.org/package=dismo

597 Hufford KM, Mazer SJ (2003) Plant ecotypes: Genetic differentiation in the age of ecological

598 restoration. Trends Ecol Evol 18:147-155. doi: 10.1016/S0169-5347(03)00002-8

599 Irl SDH, Steinbauer MJ, Messinger J, Blume-Werry G, Palomares-Martínez Á, Beierkuhnlein C,

600 Jentsch A (2014) Burned and Devoured-Introduced Herbivores, Fire, and the Endemic Flora

601 of the High-Elevation Ecosystem on La Palma, Canary Islands. Arctic, Antarct Alp Res

$602 \quad$ 46:859-869. doi: 10.1657/1938-4246-46.4.859 
603 Jakobsson M, Rosenberg NA (2007) CLUMPP: A cluster matching and permutation program for

604 dealing with label switching and multimodality in analysis of population structure.

605 Bioinformatics 23:1801-1806. doi: 10.1093/bioinformatics/btm233

606 Kalinowski ST (2005) HP-RARE 1.0: A computer program for performing rarefaction on

607 measures of allelic richness. Mol Ecol Notes 5:187-189. doi: 10.1111/j.1471-

$608 \quad 8286.2004 .00845 . x$

609 Lassueur T, Joost S, Randin CF (2006) Very high resolution digital elevation models: Do they

610 improve models of plant species distribution? Ecol Modell 198:139-153. doi:

$611 \quad$ 10.1016/J.ECOLMODEL.2006.04.004

612 Love Stowell SM, Pinzone CA, Martin AP (2017) Overcoming barriers to active interventions

613 for genetic diversity. Biodivers Conserv 26:1753-1765. doi: 10.1007/s10531-017-1330-z

614 Marrero MV, Bañares A, Carqué E (1998) La conservación del Saúco (Sambucus palmensis) en

615 el Parque Nacional de Garajonay. Conserv Veg 3:23

616 Marrero MV, Bañares Á, Carqué E (2015) Seguimiento de la flora vascular de españa. Bencomia

617 de cumbre (Bencomia exstipulata). Amagante de roques (Cistus chinamadensis). Borriza

618 del Teide (Laphangium teydeum). Saúco canario (Sambucus nigra ssp. palmensis).

619 Canutillo del Teide (Silene nocteolens). Dirección General de Calidad y Evaluación

620 Ambiental y Medio Natural, Ministerio de Agricultura, Alimentación y Medio Ambiente,

$621 \quad$ Madrid

622 Marrero MV, Carqué E, Ojeda E, Bañares A, Acevedo A (2011) Sambucus nigra ssp. palmensis.

623 In: IUCN Red List Threat. Species 2011 e.T61596A12506410

624 Moura M, Silva L, Caujapé-Castells J (2013) Population genetics in the conservation of the

625 Azorean shrub Viburnum treleasei Gand. Plant Syst Evol 299:1809-1817. doi: 
627

628

629

630

631

632

633

634

635

636

637

638

639

640

641

642

643

644

645

646

647

648

Noël F, Maurice S, Mignot A, Glémin S, Carbonell D, Justy F, Guyot I, Olivieri I, Petit C (2010) Interaction of climate, demography and genetics: a ten-year study of Brassica insularis, a narrow endemic Mediterranean species. Conserv Genet 11:509-526. doi: 10.1007/s10592010-0056-1

Nogué S, de Nascimento L, Fernández-Palacios JM, Whittaker RJ, Willis KJ (2013) The ancient forests of La Gomera, Canary Islands, and their sensitivity to environmental change. J Ecol 101:368-377. doi: 10.1111/1365-2745.12051

Oostermeijer JGB, Luijten SH, den Nijs JCM (2003) Integrating demographic and genetic approaches in plant conservation. Biol Conserv 113:389-398. doi: 10.1016/S0006$3207(03) 00127-7$

Pavlik BM (1996) Defining and measuring success. In: Falk DA, Millar CI, Olwell M (eds) Restoring diversity: Strategies for the reintroduction of endangered plants. Island Press, Washington, DC, DC, pp 127-155

Peakall R, Smouse PE (2012) GenALEx 6.5: Genetic analysis in Excel. Population genetic software for teaching and research-an update. Bioinformatics 28:2537-2539.

Pérez de Paz JP, Caujapé-Castells J (2013) A review of the allozyme data set for the Canarian endemic flora: Causes of the high genetic diversity levels and implications for conservation. Ann Bot 111:1059-1073. doi: 10.1093/aob/mct076

Pickup M, Young AG (2008) Population size, self-incompatibility and genetic rescue in diploid and tetraploid races of Rutidosis leptorrhynchoides (Asteraceae). Heredity (Edinb) 100:268-274. doi: 10.1038/sj.hdy.6801070

Piry S, Luikart G, Cornuet JM (1999) BOTTLENECK: a program for detecting recent effective 
population size reductions from allele data frequencies. J Hered 90:502-503.

650 Pritchard JK, Stephens M, Donnelly P (2000) Inference of population structure using multilocus 651 genotype data. Genetics 155:945-959. doi: 10.1111/j.1471-8286.2007.01758.x

652 Reaser JK, Meyerson LA, Cronk Q, de Poorter MAJ, Eldrege LG, Green E, Kairo M, Latasi P, 653 Mack RN, Mauremootoo J, O'dowd D, Orapa W, Sastroutomo S, Saunders A, Shine C, 654 Thrainsson S, Vaiutu L (2007) Ecological and socioeconomic impacts of invasive alien 655 species in island ecosystems. Environ Conserv 34:98-111. doi:

656 $10.1017 / \mathrm{S} 0376892907003815$

Rodríguez-Rodríguez P, Pérez de Paz PL, Sosa PA (2018) Species delimitation and conservation 658 genetics of the Canarian endemic Bethencourtia (Asteraceae). Genetica 146:199-210. doi:

Saro I, González-Pérez MA, García-Verdugo C, Sosa PA (2015) Patterns of genetic diversity in 661 Phoenix canariensis, a widespread oceanic palm (species) endemic from the Canarian

662 archipelago. Tree Genet Genomes 11:1-13. doi: 10.1007/s11295-014-0815-0

663

Silva L, Dias EF, Sardos J, Azevedo EB, Schaefer H, Moura M (2015) Towards a more holistic 664 research approach to plant conservation: The case of rare plants on oceanic islands. AoB

665 Plants 7:1-18. doi: 10.1093/aobpla/plv066

666 Sosa PA, González-González EA, González-Pérez MÁ, Pérez de Paz PL (2013) Contrasting 667 patterns of genetic differentiation in Macaronesian lineages of Ilex (Aquifoliaceae). Bot $\mathrm{J}$ 668 Linn Soc 173:258-268. doi: 10.1111/boj.12067

669 Sosa PA, González-Pérez MÁ, González-González EA, Rivero E (2011) Genetic diversity of 670 Canarian endemisms revealed by microsatellites: knowledge after one decade of analysis. 
671 In: Caujapé-Castells J, Nieto Feliner G, Fernández-Palacios JM (eds) Proceedings of the 672 Amurga International Conferences on Island Biodiversity. Maspalomas, pp 94-100

673 Sosa PA, González-Pérez MÁ, Moreno C, Clarke JB (2010) Conservation genetics of the 674 endangered endemic Sambucus palmensis Link (Sambucaceae) from the Canary Islands. 675 Conserv Genet 11:2357-2368. doi: 10.1007/s10592-010-0122-8

676 Storfer A (1999) Gene flow and endangered species translocations: a topic revisited. Biol 677 Conserv 87:173-180. doi: 10.1016/S0006-3207(98)00066-4

678 Takayama K, López-Sepúlveda P, Greimler J, Crawford DJ, Peñailillo P, Baeza M, Ruiz E, Kohl

679 G, Tremetsberger K, Gatica A, Letelier L, Novoa P, Novak J, Stuessy TF (2015)

680 Relationships and genetic consequences of contrasting modes of speciation among endemic 681 species of Robinsonia (Asteraceae, Senecioneae) of the Juan Fernández Archipelago, Chile, 682 based on AFLPs and SSRs. New Phytol 205:415-428. doi: 10.1111/nph.13000.

683 Thuiller W, Lafourcade B, Engler R, Araújo MB (2009) BIOMOD - a platform for ensemble 684 forecasting of species distributions. Ecography (Cop) 32:369-373. doi: 10.1111/j.1600$685 \quad 0587.2008 .05742 . \mathrm{x}$

686 Van Oosterhout C, Weetman D, Hutchinson WF (2006) Estimation and adjustment of 687 microsatellite null alleles in nonequilibrium populations. Mol Ecol Notes 6:255-256. doi: $688 \quad 10.1111 / \mathrm{j} .1471-8286.2005 .01082 . \mathrm{x}$

689 Vergeer P, Sonderen E, Ouborg NJ (2004) Introduction Strategies Put to the Test: Local $690 \quad$ Adaptation versus Heterosis. Conserv Biol 18:812-821. doi: 10.1111/j.1523-

$691 \quad$ 1739.2004.00562.x

692 Walsh C, and MacNally R (2013) Hiert.part: Hierarchical Partitioning. R Package v1.0693 4. http://cran.r-project.org/package=hier.part 
694 White OW, Doo B, Carine MA, Chapman MA (2016) Transcriptome Sequencing and Simple 695 Sequence Repeat Marker Development for Three Macaronesian Endemic Plant Species. 696 Appl Plant Sci 4:1600050. doi: 10.3732/apps.1600050

697 Whittaker RJ, Fernández-Palacios JM (2007) Island Biogeography. Ecology, evolution and 698 conservation, Second Edi. Oxford University Press, Oxford and La Laguna

699 Willi Y, Kleunen M van, Dietrich S, Fischer M (2007) Genetic rescue persists beyond first700 generation outbreeding in small populations of a rare plant. Proc R Soc London B Biol Sci $701 \quad 274: 2357-2364$

702 Yang JY, Ojeda DI, Santos-Guerra A, Jaén-Molina R, Caujapé-Castells J, Cronk Q (2017) 703 Population differentiation in relation to conservation: nuclear microsatellite variation in the 704 Canary Island endemic Lotus sessilifolius (Fabaceae). Conserv Genet Resour 1-9. doi: $10.1007 / \mathrm{s} 12686-017-0778-1$

706

707

FIGURE CAPTIONS

708

709

710

711

712

713

714

715

716
Fig. 1 a) Geographical situation of the Canarian archipelago. b) Adult specimen of Sambucus palmensis (c) Details of the inflorescence. (d) Fruits. Photo credits: J. Damián Esquivel Díaz. e) Map of the distribution of the individuals sampled. The 15 areas described for population management are indicated, see the locality codes in Table 1. f) La Gomera Island with the Garajonay National Park situation (purple line).

Fig. 2 a) Principal coordinate analysis (PCoA) for all Sambucus palmensis individuals sampled in Garajonay National Park (La Gomera). The individuals were represented according to their origin (reintroduced or natural). The first two axes explained $62.06 \%$ of the total variation. b) and c) Bar plots for the proportion of coancestry inferred from Bayesian 

cluster analysis implemented on STRUCTURE and CLUMPP. Figure b) includes all the individuals grouped in $K=2$ and figure c) in $K=5$ following the STRUCTURE HARVESTER results shown in Supplemental S2. Locality codes are indicated in Table 1

Fig. 3 Output maps of the ensemble model of topoclimatic suitability calibrated with: a) natural occurrences only; b) all occurrences; c) introduced occurrences only.

722

723

724

725

726

Supplemental S1 Characteristics of the 7 microsatellite markers implemented for Sambucus palmensis in La Gomera. EMBL ID: Accession number per locus. Dye: Name of each fluorescent dye per locus. Multiplex; †Load A, *Load B. F: Forward. R: Reverse

Supplemental S2 Output results from STRUCTURE HARVESTER. (A) The mean of loglikelihood values for each value of $K(1-15),(\mathrm{B})$ Ad hoc statistic based on the rate of change in the $\log$ probability of data between successive $K$ values ( $\Delta K$, following Evanno et al. (2005))

Supplemental S3 Genotypes per locality found for Sambucus palmensis in La Gomera. Unique genotypes are assigned a numeric code and shared genotypes are coded with letters from A to $\mathrm{ZZ}$

Supplemental S4 Allele frequencies for the seven microsatellites studied in Sambucus palmensis sampling sites in La Gomera. Private alleles per site are in bold and italics. Rare alleles (present in 4 sites or less) are in bold

Supplemental S5 List of the best candidates for future reintroduction programs. Individuals with unique or rare genotypes, which also presented a high individual heterozygosity and private or rare alleles were considered. ID = Code assigned to each individual, Genotype code $=$ Identification code of the genotypes assigned to each individual, H-ind = Individual heterozygosity 
740 Supplemental S6 Plot of the first two axes of the principal component analysis performed with

741 the predictors for topoclimatic suitability models

742 Supplemental S7 a) Boxplots temperature seasonality and annual precipitation of natural

743 occurrences and reintroduced occurrences. b) Response curves for temperature seasonality

744 and annual precipitation for the ensemble modelling calibrated with natural or reintroduced

745 occurrences

746 Supplemental S8 Boxplots of TSS scores for the three modelling procedures, differentiated by

$747 \quad$ algorithms 


\section{Figure 1}

Geographical distribution of Sambucus palmensis in La Gomera

a) Geographical situation of the Canarian archipelago. b) Adult specimen of Sambucus

palmensis (c) Details of the inflorescence. (d) Fruits. Photo credits: J. Damián Esquivel Díaz.

e) Map of the distribution of the individuals sampled. The 15 areas described for population

management are indicated, see the locality codes in Table 1. f) La Gomera Island with the Garajonay National Park situation (purple line). 

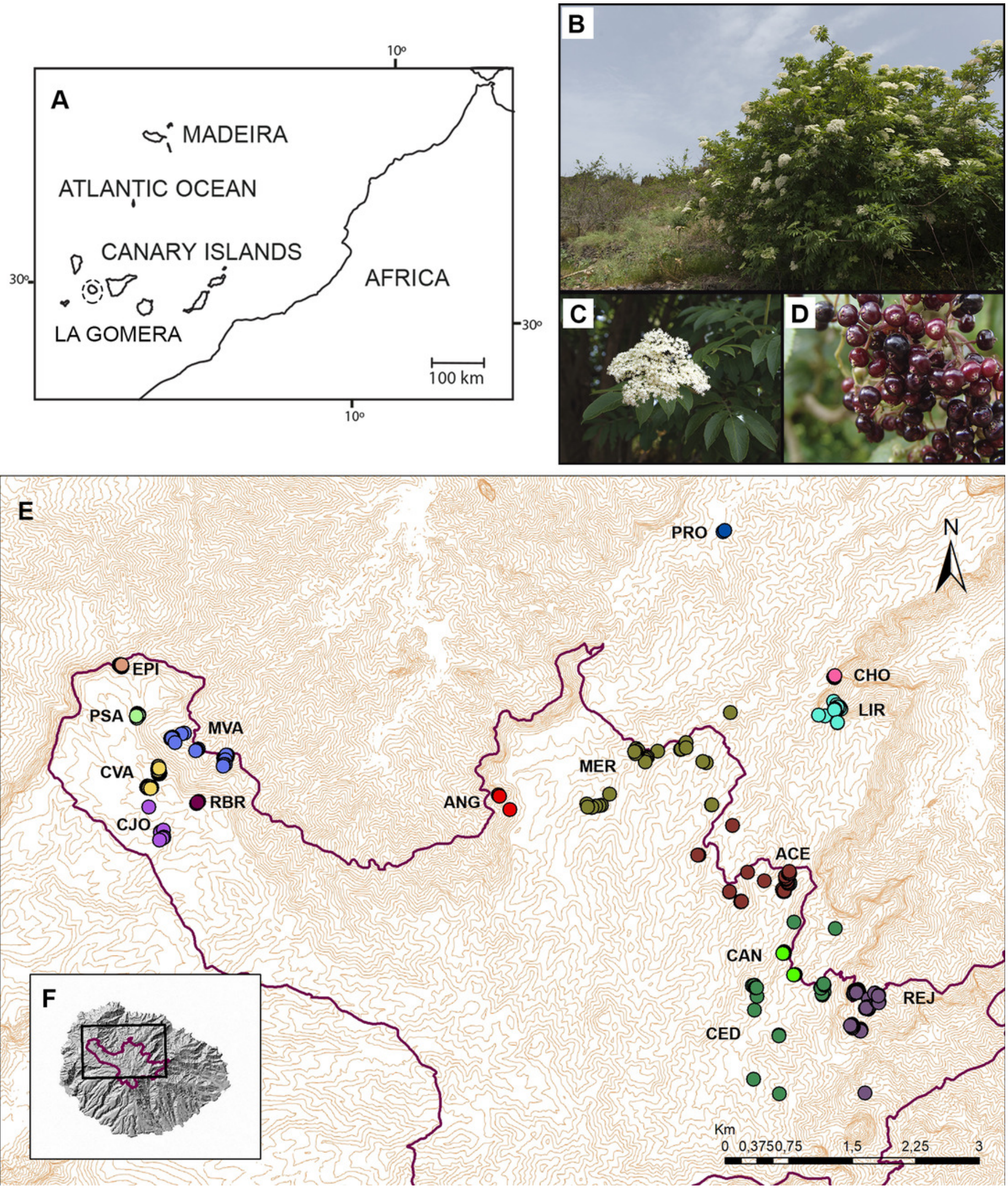


\section{Figure 2}

Genetic structure of Sambucus palmensis in the Garajonay National Park

a) Principal coordinate analysis (PCOA) for all Sambucus palmensis individuals sampled in the Garajonay National Park (La Gomera). The individuals were represented according to their origin (reintroduced or natural). The first two axes explained $62.06 \%$ of the total variation.

b) and c) Bar plots for the proportion of coancestry inferred from Bayesian cluster analysis implemented on STRUCTURE and CLUMPP. Figure b) includes all the individuals grouped in $K$ $=2$ and figure $\mathrm{c}$ ) in $K=5$ following the STRUCTURE HARVESTER results shown in Supplemental S2. Locality codes are indicated in Table 1

a)

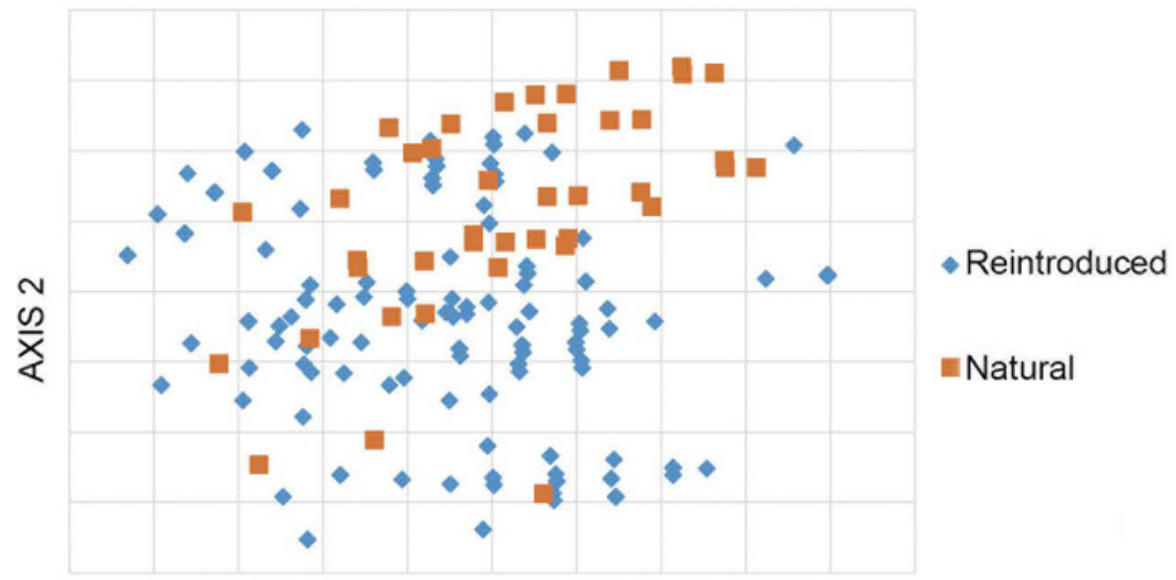

AXIS 1
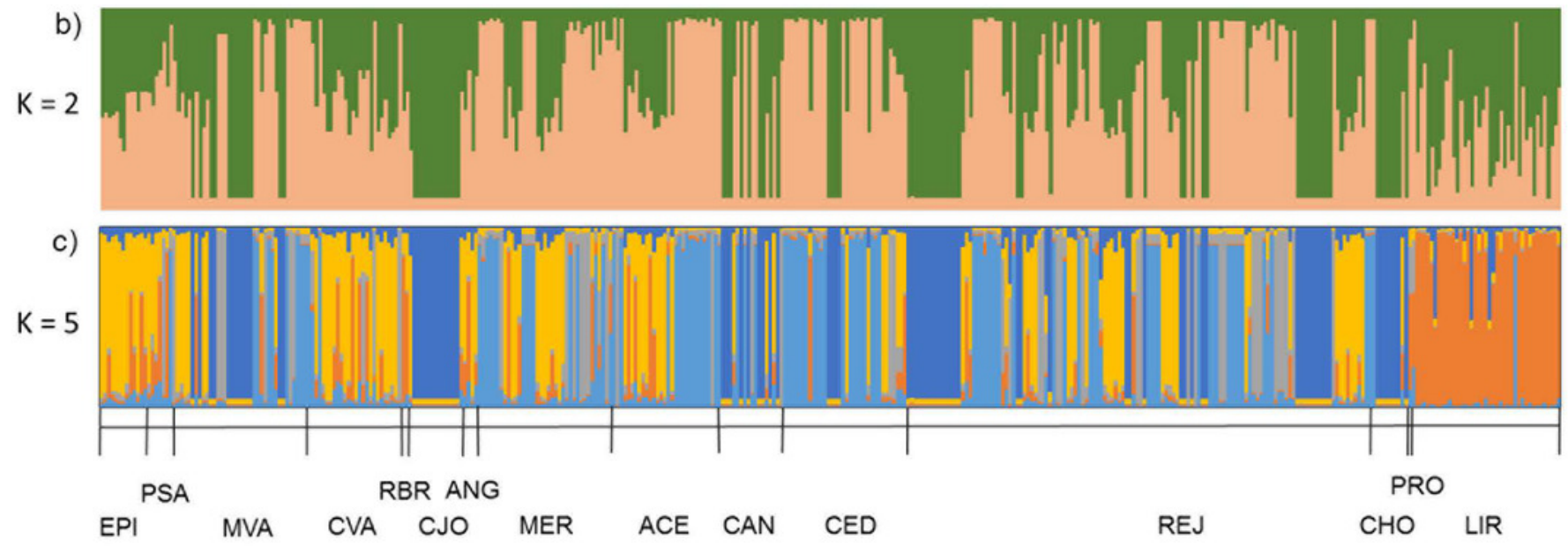
Figure 3

Output maps of the ensemble model of topoclimatic suitability calibrated with: a) natural occurrences only; b) all occurrences; $c$ ) introduced occurrences only.
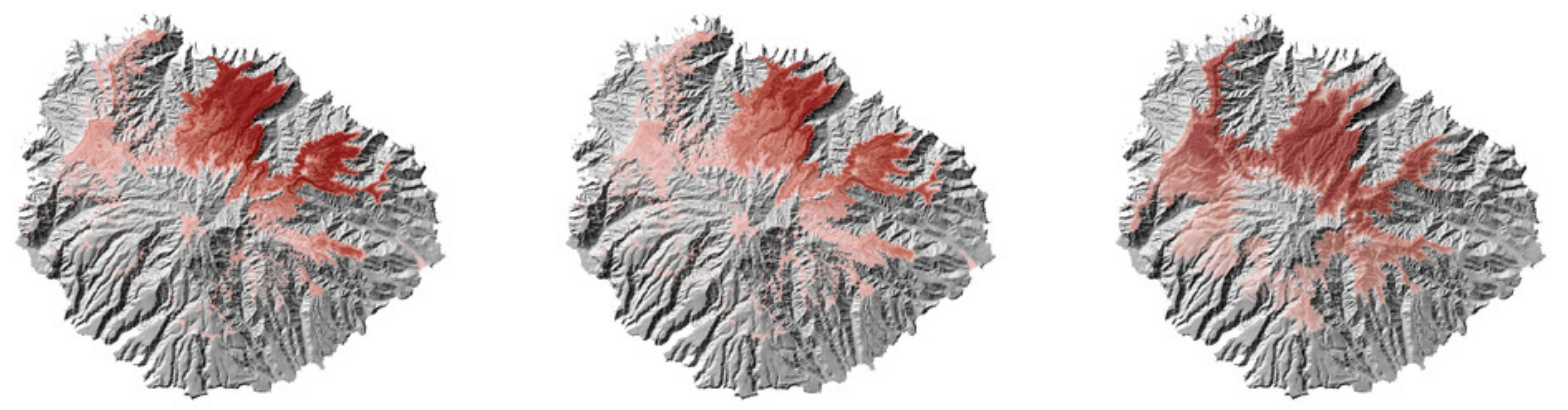

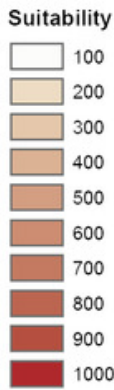

$02.25 \quad 4.5$

$13.5 \quad 18$ 


\section{Table $\mathbf{1}$ (on next page)}

Sambucus palmensis localities sampled in La Gomera.

$\mathrm{N}=$ sample size. The number of natural individuals, and number of genotypes per site are indicated. Unique genotypes are present in only one analyzed individual, while the shared genotypes were present in two or more individuals. Sites were grouped according to their geographical distribution or management area required by the National Park. 


\begin{tabular}{|c|c|c|c|c|c|c|c|}
\hline Sampling site & Acronym & $\mathrm{N}$ & $\begin{array}{r}\text { Natural } \\
\text { individuals }\end{array}$ & $\begin{array}{l}\text { Total number } \\
\text { of genotypes }\end{array}$ & $\begin{array}{r}\text { Shared } \\
\text { genotypes }\end{array}$ & $\begin{array}{r}\text { Unique } \\
\text { genotypes }\end{array}$ & $\begin{array}{r}\% \text { of unique } \\
\text { genotypes }\end{array}$ \\
\hline Acebiños & $\mathrm{ACE}$ & 31 & 1 & 25 & 21 & 4 & 16.00 \\
\hline Ancón de Candelaria & CAN & 17 & 1 & 6 & 5 & 1 & 16.67 \\
\hline Angola & ANG & 5 & - & 5 & 4 & 1 & 20.00 \\
\hline Cañada Jorge & CJO & 13 & - & 1 & 1 & 0 & 0.00 \\
\hline \multicolumn{8}{|l|}{ Cordillera } \\
\hline Vallehermoso & CVA & 25 & - & 22 & 16 & 6 & 27.27 \\
\hline El Cedro & CED & 35 & - & 21 & 17 & 4 & 19.05 \\
\hline El Chorrillo & $\mathrm{CHO}$ & 9 & - & 2 & 2 & 0 & 0.00 \\
\hline El Rejo & REJ & 129 & - & 58 & 40 & 18 & 31.03 \\
\hline Epina & EPI & 13 & - & 13 & 12 & 1 & 7.69 \\
\hline Liria & LIR & 40 & 40 & 35 & 6 & 29 & 82.86 \\
\hline Meriga & MER & 36 & 3 & 26 & 15 & 11 & 42.31 \\
\hline \multicolumn{8}{|l|}{ Meseta } \\
\hline Vallehermoso & MVA & 38 & - & 18 & 15 & 3 & 16.67 \\
\hline Palo que salta & PSA & 7 & - & 7 & 5 & 2 & 28.57 \\
\hline Presa Las Rosas & PRO & 2 & 2 & 2 & 0 & 2 & 100.00 \\
\hline Raso de La Bruma & RBR & 3 & - & 3 & 1 & 2 & 66.67 \\
\hline Average per site & & 26.9 & 9.4 & 16.2 & 10.6 & 5.6 & 31.71 \\
\hline Total & & 402 & 47 & 147 & 63 & 84 & 57.14 \\
\hline
\end{tabular}

2 


\section{Table 2 (on next page)}

Genetic diversity indices for Sambucus palmensis in La Gomera.

$N=$ sample size; $\mathrm{Na}=$ average of alleles per locus; $P a=$ number of private alleles; $R a=$ rare alleles (present in 4 localities or less); $A r=$ rarefied allelic richness; $P a r=$ rarefied private allelic richness, $H_{0}=$ observed heterozygosity; $H_{\mathrm{e}}=$ unbiased expected heterozygosity. 


\begin{tabular}{lrrrrrrrr}
\hline Sampling site & $\boldsymbol{N}$ & $\boldsymbol{N a}$ & $\boldsymbol{P a}$ & $\boldsymbol{R a}$ & $\boldsymbol{A r}$ & $\boldsymbol{P a r}$ & $\boldsymbol{H}_{\boldsymbol{o}}$ & $\boldsymbol{H}_{\boldsymbol{e}}$ \\
\hline Acebiños & 31 & 2.71 & - & 1.00 & 1.73 & 0.02 & 0.406 & 0.373 \\
Ancón de & & & & & & & & \\
Candelaria & 17 & 2.86 & - & 2.00 & 1.95 & 0.04 & 0.605 & 0.491 \\
Angola & 5 & 2.14 & - & - & 1.87 & 0.00 & 0.600 & 0.467 \\
Cañada Jorge & 13 & 1.71 & - & - & 1.65 & 0.00 & 0.714 & 0.371 \\
Cordillera & & & & & & & & \\
Vallehermoso & 25 & 2.57 & - & - & 1.88 & 0.02 & 0.606 & 0.466 \\
El Cedro & 35 & 2.57 & - & - & 1.71 & 0.01 & 0.366 & 0.368 \\
El Chorrillo & 9 & 2.14 & - & - & 1.74 & 0.00 & 0.698 & 0.415 \\
El Rejo & 129 & 2.86 & - & 2.00 & 1.93 & 0.05 & 0.549 & 0.479 \\
Epina & 13 & 2.14 & - & - & 1.89 & 0.00 & 0.692 & 0.486 \\
Liria & 40 & 2.29 & 3.00 & 5.00 & 1.73 & 0.26 & 0.421 & 0.376 \\
Meriga & 36 & 2.71 & 1.00 & 1.00 & 1.7 & 0.03 & 0.425 & 0.359 \\
Meseta & & & & & & & & \\
Vallehermoso & 38 & 2.86 & - & 2.00 & 1.94 & 0.03 & 0.564 & 0.484 \\
Palo que salta & 7 & 2.29 & - & 1.00 & 1.71 & 0.03 & 0.469 & 0.364 \\
Presa Las Rosas & 2 & 1.57 & - & 2.00 & 1.57 & 0.23 & 0.500 & 0.357 \\
Raso de La Bruma & 3 & 2.14 & - & - & 1.93 & 0.00 & 0.667 & 0.495 \\
Average over pop & 26.86 & 2.37 & 0.27 & 1.07 & 1.80 & 0.05 & 0.552 & 0.423 \\
\hline All individuals & 402 & 3.71 & - & - & - & - & 0.519 & 0.462 \\
Reintroduced & 355 & 3.14 & 2.00 & - & 2.82 & 0.16 & 0.532 & 0.462 \\
Natural & 47 & 3.43 & 4.00 & - & 3.43 & 0.77 & 0.426 & 0.402 \\
\hline
\end{tabular}




\section{Table 3(on next page)}

AMOVA analysis for Sambucus palmensis in La Gomera.

Individuals were grouped according to their sampling site and origin (natural or reintroduced). ${ }^{* * *} P<0.001$ 


\begin{tabular}{lrrrrr}
\hline Source of variation & $\begin{array}{l}\text { Degrees of } \\
\text { freedom }\end{array}$ & $\begin{array}{l}\text { Sum of } \\
\text { squares }\end{array}$ & $\begin{array}{l}\text { Variance of } \\
\text { components }\end{array}$ & $\begin{array}{l}\text { Percentage } \\
\text { of variation }\end{array}$ & F-statistics \\
\hline All sites & 14 & 14.7 & 0.012 & 2.5 & \\
Among groups & 789 & 370.0 & 0.469 & 97.5 & $0.025^{\star * \star}$ \\
Within groups & 803 & 384.6 & 0.481 & & \\
Total & & & & & \\
Natural vs. Reintroduced & 1 & 2.9 & 0.014 & 2.9 & \\
Among groups & 802 & 381.8 & 0.476 & 97.1 & $0.029^{* * *}$ \\
Within groups & 803 & 384.6 & 0.490 & & \\
Total & & & &
\end{tabular}

